\title{
Deformation Mechanisms in Compression-Loaded, Stand-Alone Plasma-Sprayed Alumina Coatings
}

\author{
Rodney W. Trice, ${ }^{*, \dagger, \S}$ David W. Prine, ${ }^{\ddagger}$ and K. T. Faber ${ }^{*, \dagger}$ \\ Department of Materials Science and Engineering, Robert R. McCormick School of Engineering and Applied Science,
} and Infrastructure Technology Institute, Northwestern University, Evanston, Illinois 60208

\begin{abstract}
Cylindrical, stand-alone tubes of plasma-sprayed alumina were tested in compression in the axial direction at room temperature, using strain gauges to monitor axial and circumferential strains. The primary compression-loading profile used was cyclic loading, with monotonically increased peak stresses. Hysteresis was observed in the stress-strain response on unloading, beginning at a peak stress of $50 \mathrm{MPa}$. The modulus decreased as the maximum applied stress increased. The stress-strain response was only linear at low stresses; the degree of nonlinearity at high stresses scaled with the stress applied. One-hour dwells at constant stress at room temperature revealed a time-dependent strain response. Using transmission electron microscopy and acoustic emission to investigate deformation mechanisms, the stressstrain response was correlated with crack pop-in, growth, and arrest. It is proposed that the numerous defects in plasmasprayed coatings, including porosity and microcracks, serve as sites for crack nucleation and/or propagation. As these small, nucleated cracks extend under the applied stress, they propagate nearly parallel to the loading direction along interlamellae boundaries. With increasing stress, these cracks ultimately link, resulting in catastrophic failure.
\end{abstract}

\section{Introduction}

$\mathrm{P}$ LASMA-SPRAYED coatings are frequently used as thermal-barrier coatings (TBCs) or wear-resistant coatings. Mechanical investigations of these coatings are often performed while the coating is still on the metallic substrate. ${ }^{1,2}$ This experimental approach is reasonable, because interaction of a coating and its underlying substrate at high temperatures often results in new failure origins, such as the thermally grown oxide ${ }^{3,4}$ between the yttria-stabilizedzirconia (YSZ) coating and the MCrAlY bondcoat (where $\mathrm{M}=\mathrm{Ni}$, $\mathrm{Cr}$, and $\mathrm{Fe})^{5,6}$ in TBCs. However, evaluation of the intrinsic mechanical response of the coating is also critical in the design of TBC or wear-resistant coating systems. For example, the elastic modulus is essential for determining the strain that the coating will experience during service. Changes in modulus, whether caused by sintering effects ${ }^{7}$ or the accumulation of damage, are also important to evaluate. The subtle mechanical response of plasmasprayed coatings, such as the strain hysteresis observed on unloading the sample, is often undetectable while the coating is attached

J. Petrovic-contributing editor

Manuscript No. 188737. Received February 1, 2000; approved June 8, 2000.

Supported by the U. S. Department of Energy, Federal Energy Technology Center, under Cooperative Agreement No. DE-FC21-92MC29061, Subcontract No. 96-01SR047.

${ }^{\star}$ Member, American Ceramic Society.

Department of Materials Science and Engineering, Robert R. McCormick School of Engineering and Applied Science.

${ }^{\S}$ Now with School of Materials Engineering, Purdue University, West Lafayette, IN.

IInfrastructure Technology Institute. to the substrate. Thus, an understanding of the intrinsic mechanical response of plasma-sprayed coatings greatly assists in the development of TBCs and wear-resistant coatings with extended lifetimes.

Previous research has investigated stand-alone plasma-sprayed coatings, focusing on mechanical evaluation of very thick coatings $(>1.2-6 \mathrm{~mm}) .{ }^{8-10}$ Although systems such as diesel engines require thick coatings, there are numerous wear and TBC applications where a thick coating is not representative of the material as used in service. Furthermore, the microstructure of thick coatings may not be equivalent to the microstructure of thinner $(\leq 300 \mu \mathrm{m})$ coatings. $^{11}$

In the current research, stand-alone coatings were tested using a cylindrical geometry with a thickness approaching 200-300 $\mu \mathrm{m}$. Although the cylindrical geometry has been used before, ${ }^{12,13}$ it was modified in the present study so that duplicate samples could be fabricated during a single plasma-spray run. Compression loading was chosen because it represents actual loading conditions observed by both TBCs and wear coatings during normal service. Although alumina is not a feasible TBC, the testing methods described could be adapted easily for stand-alone coatings of the standard TBC material ( $7 \mathrm{wt} \% \quad \mathrm{Y}_{2} \mathrm{O}_{3}-\mathrm{ZrO}_{2}$ ). The deformation mechanisms associated with these complex materials have been verified, using transmission electron microscopy (TEM) and acoustic emission (AE) methods.

\section{Experimental Procedure}

\section{(1) Sample Fabrication and Physical Testing}

The plasma-spray equipment used to fabricate samples included a control system with an F4 gun (Model No. A-3000, Plasma Technik Grün, Siegen, Germany). The gun assembly was mounted on a seven-axis robot (Model No. IRB 2000, Asea Brown Boveri, Ltd., Madrid, Spain).

Stand-alone coatings with cylindrical geometry ${ }^{\dagger \dagger}$ were manufactured by first spraying an aluminum powder (54NS-1, Sulzer Metco, Westbury, NY) onto a $300 \mathrm{~mm}$ long alumina rod. The aluminum powder was $\approx 30 \mu \mathrm{m}$ in diameter and injected into the plasma using an externally mounted straight-through injector. Each alumina rod was $12.7 \mathrm{~mm}$ in diameter, with a wall thickness of $3.2 \mathrm{~mm}$, and was mounted in the center of a turntable that was rotated at $200 \mathrm{rpm}$ during spraying. The plasma gun traversed the length of the rod, depositing a thin layer $(\approx 150 \mu \mathrm{m})$ of aluminum. The aluminum layer was subsequently lightly sanded and gritblasted.

Next, a 200-300 $\mu \mathrm{m}$ thick alumina layer was sprayed onto the aluminum-coated alumina rod, using a power of $35 \mathrm{~kW}$. The alumina powder (Al-1110-HP, Praxair Specialty Ceramics, Woodinville, WA) used to fabricate the specimens was fed into the plasma via a small-particle plasma-spray injector, ${ }^{14}$ using a conventional disk feeder. The mean particle diameter was $9.1 \mu \mathrm{m}$.

\footnotetext{
${ }^{\dagger}$ The maximum stress before failure for this sample geometry is one order of magnitude less than that required for buckling.
} 
Spray distance, as measured from the center hole of the injector to the substrate, was $7 \mathrm{~cm}$. The radial distance, held constant at 10 $\mathrm{mm}$, was defined as the distance from the injector to the centerline of the plume. The primary-gas (argon) and secondary-gas (hydrogen) flows were 35 and 11 standard liters per minute (SLM), respectively. The carrier-gas (argon) flow was $5 \mathrm{slm}$. The plasma gun was moved at rate of $350 \mathrm{~mm} / \mathrm{s}$ along the length of the tube. Cooling air, at a pressure of $0.33 \mathrm{MPa}$, was forced down the open hole of the tube during the spraying of the alumina coatings.

Small tubes were cut from the long rod into $25 \mathrm{~mm}$ lengths, with the faces of each tube machined parallel, using a lathe and diamond-based tooling. Following outer diameter measurements of the coating, the tubes were immersed in a weak solution of $\mathrm{HCl}$ to dissolve the aluminum, releasing the plasma-sprayed alumina tube from the underlying alumina substrate. The stand-alone tubes were then dried and their thicknesses measured. The bulk density of each stand-alone tube was determined by the immersion method. ${ }^{15}$ Plasma-sprayed stand-alone tubes were labeled as PS- $x$, where $x$ is the individual sample number. One tube (HT-1) was heat-treated for $50 \mathrm{~h}$ at $1300^{\circ} \mathrm{C}$ before testing.

Using $K_{\alpha} \mathrm{X}$-ray diffraction and calibrated standards described in previous research, ${ }^{11}$ the percentage of $\alpha-\mathrm{Al}_{2} \mathrm{O}_{3}$ was calculated, with the remaining coating comprised of $\gamma-\mathrm{Al}_{2} \mathrm{O}_{3}$. The amount of stable $\alpha-\mathrm{Al}_{2} \mathrm{O}_{3}$ phase was determined to be $\approx 9 \mathrm{wt} \%$. Based on these values, a theoretical density of $\approx 3.68 \mathrm{~g} / \mathrm{cm}^{3}$ was calculated, assuming densities of 3.65 and $4.0 \mathrm{~g} / \mathrm{cm}^{3}$ for $\gamma-\mathrm{Al}_{2} \mathrm{O}_{3}$ and $\alpha-\mathrm{Al}_{2} \mathrm{O}_{3}$, respectively.

TEM samples were fabricated from a tube mechanically tested through failure and the heat-treated tube, using the wedgemounting technique and low-angle argon ion milling to electron transparency. Samples were viewed in cross sections cut parallel to the axial direction, such that any lamellae sliding associated with deformation would be observed. Imaging was performed in a cFEG TEM at $200 \mathrm{kV}$ (Model No. HF2000, Hitachi Co., Ltd., Tokyo, Japan).

\section{(2) Mechanical Testing}

A schematic of a stand-alone coating is given in Fig. 1(a), showing the orientation of the strain gauges used to monitor the strain response. Gauges (Models No. EA-06-125BZ-350, Measurements Group, Raleigh, NC) $3.2 \mathrm{~mm}$ long by $1.6 \mathrm{~mm}$ wide were bonded with a small amount of epoxy (AE-10/15 adhesive kit, Measurements Group), with a bondline thickness of 5-10 $\mu \mathrm{m}$, measured by scanning electron microscopy (SEM). Because the modulus of the polyimide gauge and adhesive was approximately one order of magnitude less than that of the as-sprayed alumina, it was not expected to influence measurements. Two axially oriented gauges, bonded on opposite sides of each tube, were used to measure the axial strain response $\left(\varepsilon_{22}\right)$. The difference in $\varepsilon_{22}$ between the two gauges was used to assess alignment. The individual $\varepsilon_{22}$ values were typically no more than $6 \%$ different during testing, and often the difference between these two gauges was much less $(<1 \%)$. A single circumferential gauge was used to monitor the circumferential strain $\left(\varepsilon_{11}\right)$.

Samples were tested in compression between two steel platens in a commercial load frame (Model No. 808 Electromechanical Test System, MTS Systems, Minneapolis, MN) (see Fig. 1(b)). Tungsten carbide (WC) inserts were placed between the platen and the sample to prevent damage of the soft steel by the ceramic tube. Also, self-adjusting spherical washers were used to assist load alignment. Two loading profiles were used, both under load feedback. In the first profile, cyclic loading with monotonically increasing applied stresses, the maximum applied stress was increased with each successive loading/unloading cycle. For example, sequential loading/unloading profiles from 25 to $200 \mathrm{MPa}$ in $25 \mathrm{MPa}$ increments were performed. Beyond $200 \mathrm{MPa}$, the stress increment was $50 \mathrm{MPa}$ through failure. Strain was monitored during loading and unloading. The loading and unloading rates were both $20 \mathrm{~N} / \mathrm{s}$. In the second loading profile, a $1 \mathrm{~h}$ hold at a constant stress was used, with the strain response monitored over time. The relative humidity during mechanical testing was $\approx 40 \%-$ $50 \%$.

The stress in each tube was calculated by dividing load by cross-sectional area. The elastic modulus in the axial direction was calculated by dividing stress by the average of the two axial gauge responses in the initial linear portion of the stress-strain curve. The strain offset, or permanent deformation, of the coating was calculated by subtracting the average axial strain on loading (at 5 $\mathrm{MPa}$ ) from the average axial strain on unloading (also at $5 \mathrm{MPa}$ ).

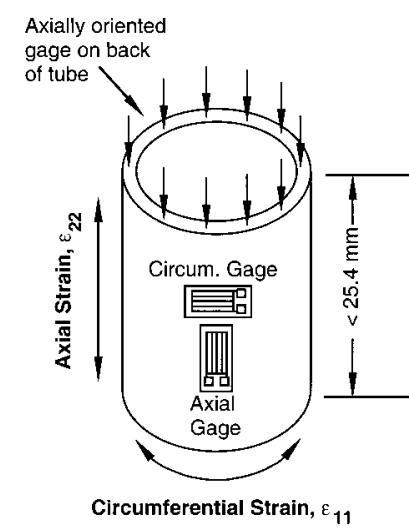

(a)

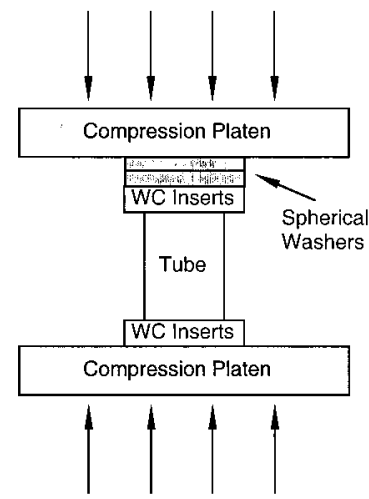

(b)

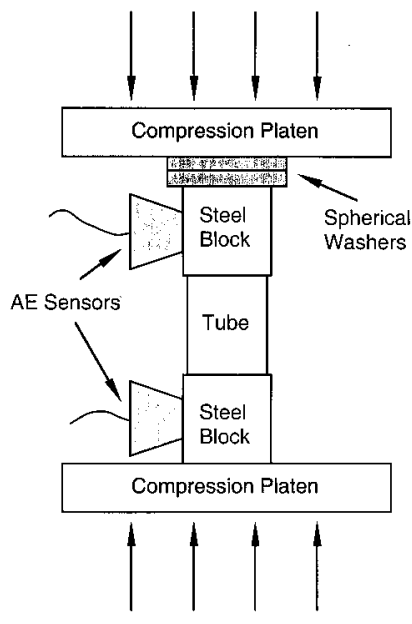

(c)

Fig. 1. (a) Schematic of stand-alone coating test sample with strain gauges and test setup used for (b) samples PS-1 through PS-5 and HT-1 and (c) samples PS-6 and PS-7. 
Poisson's ratio, $\nu$, was calculated by dividing $-\varepsilon_{11}$ by the average $\varepsilon_{22}$. Data from the three strain gauges, as well as load and time, were collected at a rate of $10 \mathrm{~s}^{-1}$.

Because AE signals have been linked with crack-propagation events, ${ }^{16,17}$ selected tests were equipped with AE sensors. The sensors were mounted perpendicular to the loading direction, on rectangular steel blocks in contact with the stand-alone tubes (see Fig. 1(c)). No WC inserts were used between the ceramic tube and the steel blocks, to minimize the number of interfaces and, thus, the acoustic losses. A small amount of silicon-based grease was used to provide reliable acoustic coupling between the sensors/ metallic-block interface and the metallic-block/ceramic-tube interface. The piezoelectric sensors (Models No. SE150-M, Dunegan Engineering Consultants, Inc., San Juan Capistrano, CA) had sensitivity peaks at $150 \mathrm{kHz}$. Preamplifiers with $43 \mathrm{~dB}$ gain were used. The AE and load/stroke data were recorded and analyzed with a digital AE monitor (Model No. AMS3, Vallen-Systeme $\mathrm{GmbH}$, Icking, Germany), communicating with a standard PC. The AE system was calibrated before each test, by applying a series of electronic pulses to each sensor and recording the received signals at the other sensor. The calibration step ensured consistency from run to run, and any problems with acoustic coupling, sensors, or connecting cables were detected quickly. Following the calibration and verification procedures, the tubes were mechanically tested.

\section{Results}

\section{(1) Microstructure}

Figure 2(a) is a representative polished and circumferentially cut cross section of a tube observed under SEM. The sample was viewed in this orientation to check for through-thickness cracks; none were observed.

The cross section of the coating is typical for plasma spray, with some pores $>1 \mu \mathrm{m}$ observed. Figure 2(b) is a bright-field TEM image from a sample that was oriented such that cross sections cut parallel to the long axis of the cylinder (see schematic in Fig. 2) were viewed. This image shows, under ideal circumstances, how lamellae are oriented as a result of the spraying, with respect to the loading. Typical of plasma-sprayed coatings are submicrometer porosity and microcracks, with most of the small porosity located at the interlamellae boundaries.

\section{(2) Overview of Physical and Mechanical Property Results}

Table I is an overview of the physical and mechanical results for each of the cylinders tested. All samples were tested in the as-sprayed condition, with the exception of HT-1. All of the tubes were subject to the increased-stress cyclic loading, whereas only two tubes (PS-6 and HT-1) were held at a constant stress. The tubes varied from $86 \%$ to $89 \%$ dense, based on a theoretical density of $3.68 \mathrm{~g} / \mathrm{cm}^{3}$ for the as-sprayed coating. The theoretical density of HT-1 was $4.0 \mathrm{~g} / \mathrm{cm}^{3}$ because it fully converted to $\alpha-\mathrm{Al}_{2} \mathrm{O}_{3}$ after heat treatment. Thus, although the measured density increased during heat treatment $\left(3.48 \mathrm{~g} / \mathrm{cm}^{3}\right)$, the theoretical density concomitantly increased with the polymorphic transformation, resulting in a body $87 \%$ dense. The failure strength of the tubes varied from 225 to $500 \mathrm{MPa}$. In several instances during cyclic tests, the tubes failed at lower loads than they had previously sustained. For example, PS-2 had been loaded previously to 350 $\mathrm{MPa}$; on reloading, the sample fractured at $295 \mathrm{MPa}$. The strain-at-failure ranged from $0.35 \%$ to $0.83 \%$ for the tubes tested. Low strains were correlated with low strength. Modulus was calculated on the initial loading to $25 \mathrm{MPa}$ and on the final loading, just before fracture. In every case, as-sprayed tubes displayed a lower modulus just before fracture than during the initial loading. The modulus of the heat-treated tube was twice that of the as-sprayed tubes and remained constant through the various loading/unloading cycles.

\section{(3) Mechanical Response}

The mechanical response included (1) stress-strain hysteresis and permanent deformation on unloading, (2) a reduction in elastic

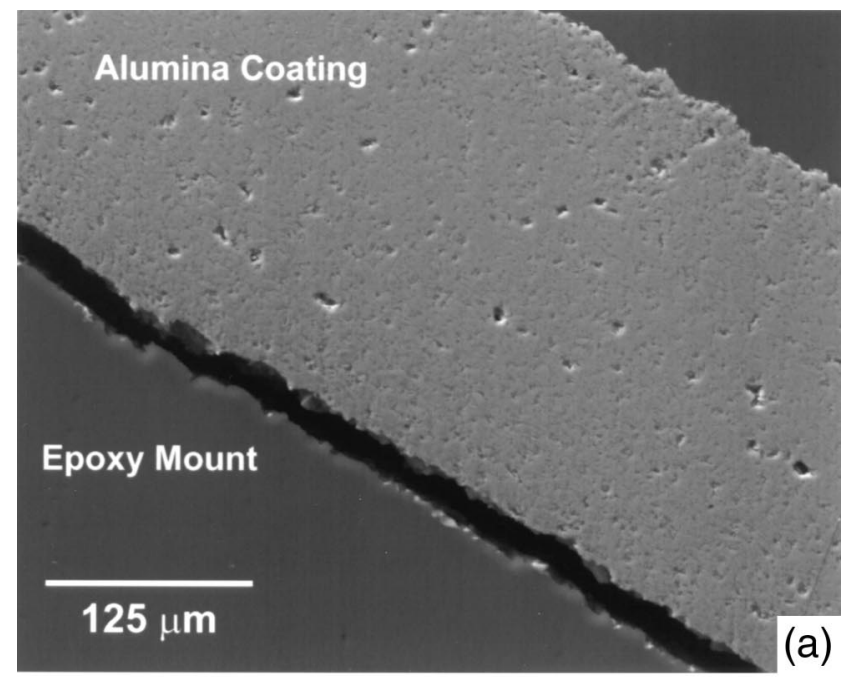

\section{Load Direction}
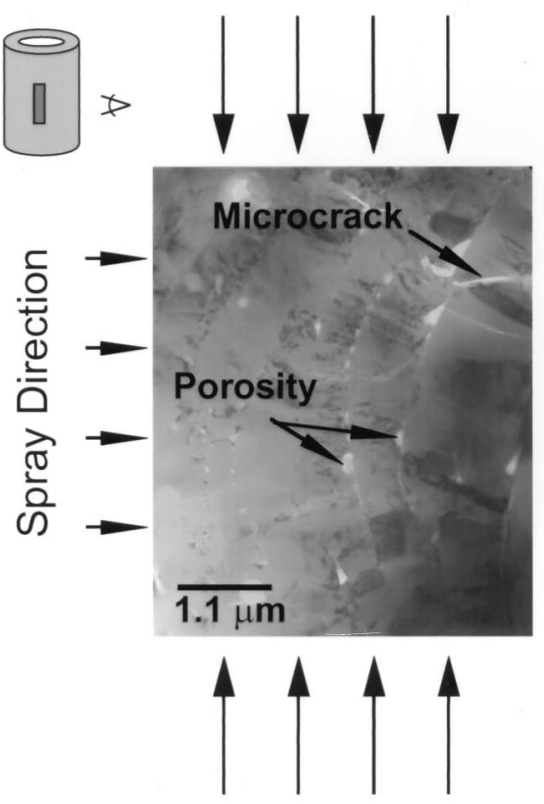

(b)

Fig. 2. (a) Polished, circumferentially oriented cross section of a typical alumina coating and (b) bright-field TEM image, indicating the orientation of the lamellae with respect to loading. Tubes were viewed in cross sections cut in the axial orientation, as shown in the schematic.

modulus with increased-stress cyclical loading, and (3) timedependent stress-strain phenomena.

(A) Stress-Strain Hysteresis: Figure 3 illustrates the typical mechanical response of a tube subjected to increased-stress cyclical loading. Four cycles are represented, with peak stresses ranging from 50 to $350 \mathrm{MPa}$. The stress-strain responses, which have been offset for clarity, exhibited several transitions. The response was linear for applied stresses between 0 and $\approx 100 \mathrm{MPa}$. At higher applied stresses, the stress-strain response often was nonlinear over the entire loading profile. Also occurring at higher applied stresses, for example at $350 \mathrm{MPa}$, was an increase in the apparent modulus as the strain increased. This increase is believed to result from densification of the tube because of closure of the microcracks oriented perpendicular to the applied compressive stress.

Significant hysteresis was apparent between the loading and unloading portions of the curve. This behavior has been observed previously in plasma-sprayed YSZ. ${ }^{8}$ The maximum width of the hysteresis also increased with increased loading, varying from 50 to $400 \mu \varepsilon$ at 50 and $350 \mathrm{MPa}$, respectively. However, no hysteresis 
Table I. Overview of Physical and Mechanical Tests

\begin{tabular}{|c|c|c|c|c|c|c|c|c|}
\hline $\begin{array}{c}\text { Sample } \\
\text { designation }\end{array}$ & $\begin{array}{c}\text { Thickness } \\
(\mu \mathrm{m})\end{array}$ & $\begin{array}{l}\text { Density } \\
\left(\mathrm{g} / \mathrm{cm}^{3}\right)\end{array}$ & $\begin{array}{l}\text { Percent } \\
\text { dense }^{\dagger}\end{array}$ & $\begin{array}{l}\text { Strength } \\
\text { (MPa) }\end{array}$ & $\begin{array}{c}\text { Strain at } \\
\text { failure }(\%)\end{array}$ & $\underset{(\%)}{\operatorname{Maximum} \text { strain }}$ & $\begin{array}{l}\text { Initial modulus } \\
\quad(\mathrm{GPa})\end{array}$ & $\underset{(\mathrm{GPa})}{\text { Final modulus }}$ \\
\hline PS-1 & 308 & 3.26 & 89 & 493 & 0.70 & 0.7 & $96 \pm 3$ & $80 \pm 3$ \\
\hline PS-2 & 307 & 3.16 & 86 & 295 & 0.44 & $0.53(350 \mathrm{MPa})$ & $81 \pm 3$ & $74 \pm 3$ \\
\hline PS-4 & 290 & 3.16 & 86 & 380 & 0.63 & 0.63 & $74 \pm 3$ & $59 \pm 3$ \\
\hline PS-5 & 298 & 3.17 & 86 & 225 & 0.35 & 0.35 & $75 \pm 3$ & $67 \pm 3$ \\
\hline PS $-6^{\S}$ & 288 & 3.28 & 89 & & & & & \\
\hline
\end{tabular}

${ }^{\dagger}$ Based on a theoretical density of $3.68 \mathrm{~g} / \mathrm{cm}^{3}$. $\quad$ Calculated from the initial slope of the stress-strain loading response, during which failure occurred. ${ }^{\S}$ Sample configured with $\mathrm{AE}$ sensors. "ISample heat-treated for $50 \mathrm{~h}$ at $1300^{\circ} \mathrm{C}$; sample was $100 \% \alpha-\mathrm{Al}_{2} \mathrm{O}_{3}$ after the heat treatment, with a theoretical density of $4.0 \mathrm{~g} / \mathrm{cm}^{3}$.

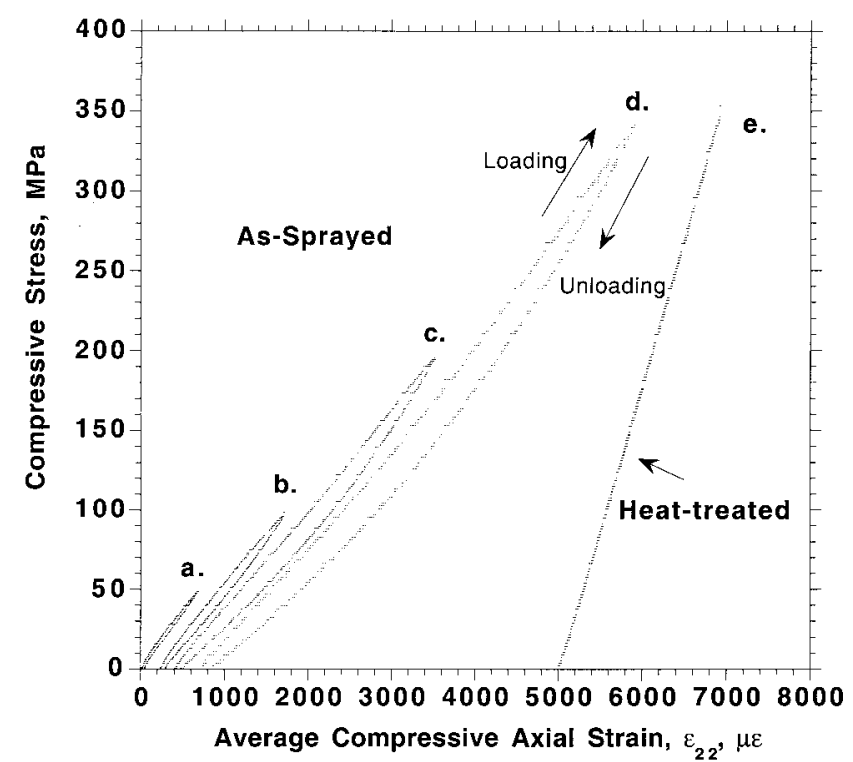

Fig. 3. Loading/unloading curves (a)-(d) for an as-sprayed tube (PS-4) and (e) from a sample heat-treated for $50 \mathrm{~h}$ at $1300^{\circ} \mathrm{C}$ (HT-1). Hysteresis was observed in all of the as-sprayed tubes tested under compression.

was observed in the sample subjected to $50 \mathrm{~h}$ of heat treatment at $1300^{\circ} \mathrm{C}$ and then tested at room temperature (see Fig. 3).

Figure 4 is a plot of the strain profile and AE signals versus time for a sample subject to increased-stress cyclical loading at stresses of 175 and $200 \mathrm{MPa}$. Focusing on Fig. 4(a), most of the AE signals were observed after the applied stress reached the peak stress of the previous cycle, in this case $150 \mathrm{MPa}$ (denoted by a "+" on the figure). This same phenomenon was apparent when the sample was loaded to $200 \mathrm{MPa}$ (see Fig. 4(b)). Here, most of the AE signals appear beyond $175 \mathrm{MPa}$. This response, known as the Kaiser effect or "the absence of detectable AE at a fixed sensitivity level, until previously applied stress levels are exceeded,"18 is an indication of crack propagation rather than frictional noise. The latter would be expected to occur randomly during all portions of the load cycle. From Fig. 4, it is clear that fracture events occurred both during loading, primarily beyond the previously sustained load, and on unloading.

On unloading at applied stresses $>50 \mathrm{MPa}$, the strain did not return to zero, but rather indicated a permanent negative offset. Physically, this result means that the sample was compressed during testing. Figure 5 shows a plot of the offset versus the maximum applied stress for three samples that underwent increased-stress cyclic loading. The permanent offset is proportional to the applied stress during cyclical loading. In cases where the sample was loaded to the same peak stress several times in succession (not shown), for example to $75 \mathrm{MPa}$, the amount of additional permanent deformation decreased with each cycle. On
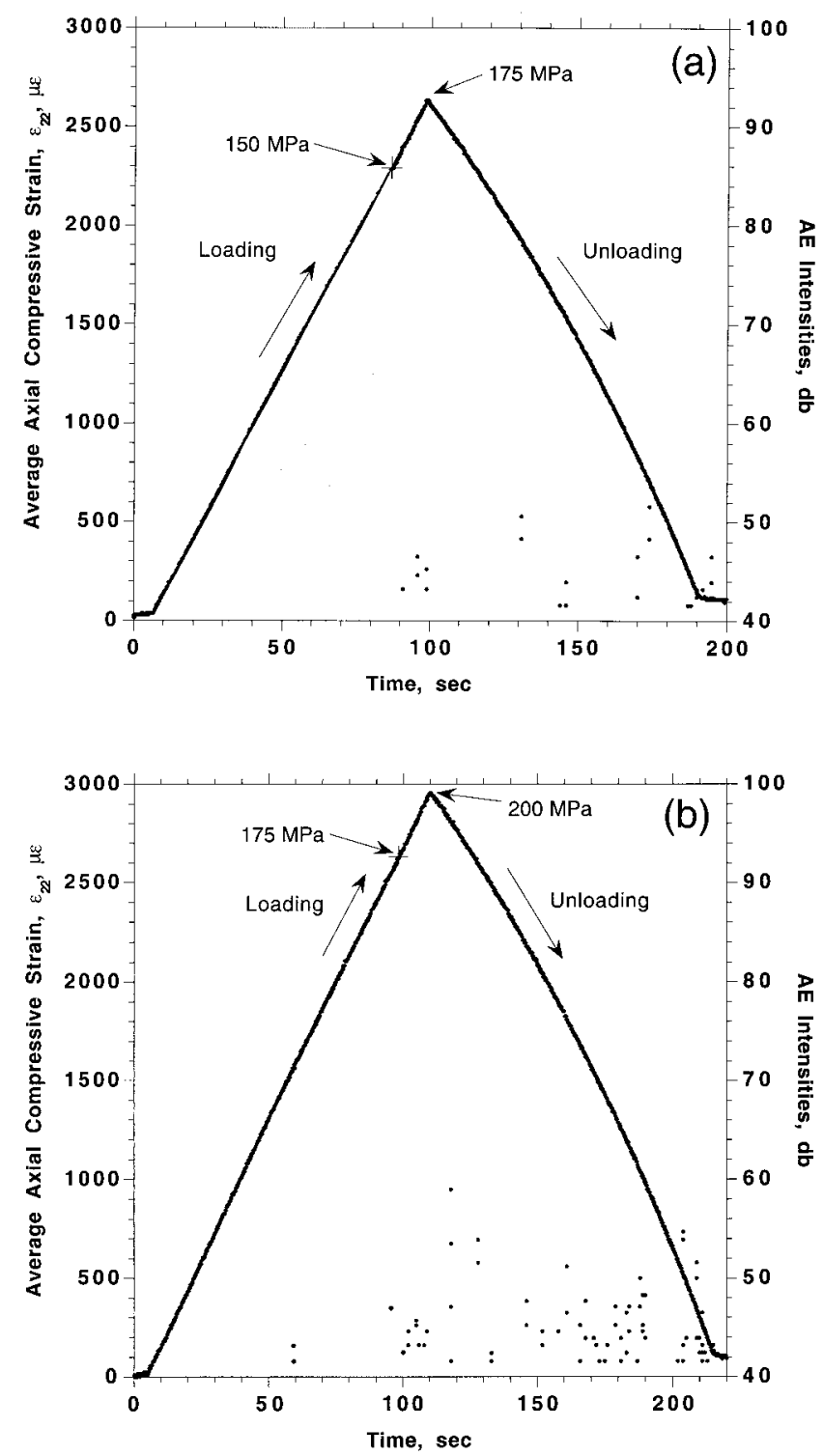

Fig. 4. Plot of strain and AE events versus time for (a) 175 and (b) 200 MPa loading/unloading cycles (PS-7) (shaded area represents stress applied in the previous loading/unloading cycle; $(\bullet)$ acoustic event).

the third loading/unloading cycle, no further permanent deformation was observed. Thus, the damage done to the sample diminished with repeated application of the same stress.

Strain hysteresis is not limited to the axial direction, as shown in Fig. 6, a plot of both axial and circumferential strain of a sample loaded to $250 \mathrm{MPa}$. Clearly, there is a difference between the loading and unloading stress-strain response in the circumferential 


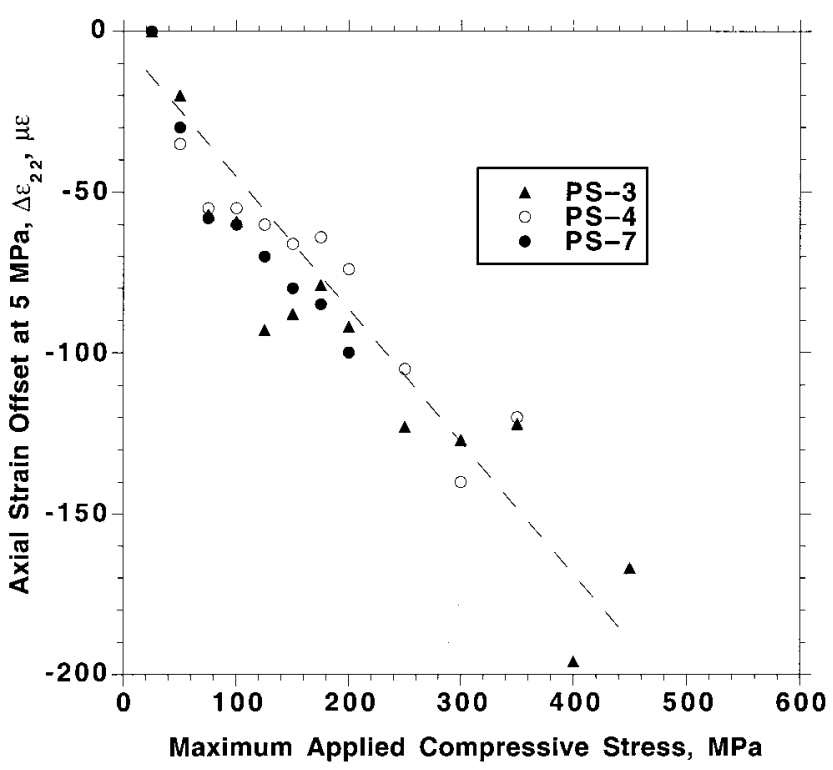

Fig. 5. Permanent offset, as a function of the applied compressive stress, for several tubes.

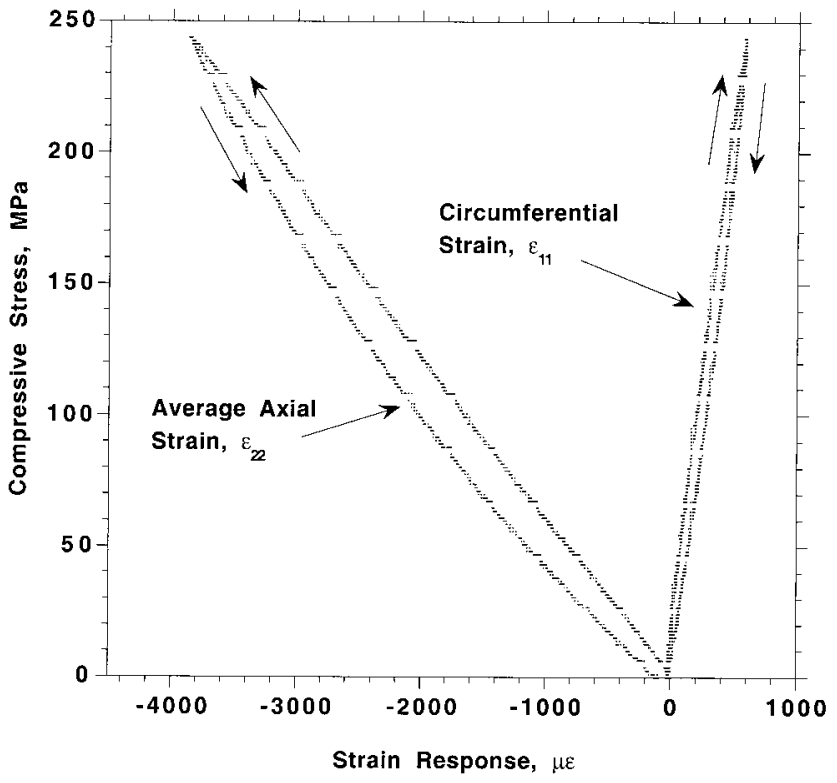

Fig. 6. Plot of $\varepsilon_{22}$ and $\varepsilon_{11}$, as a function of loading, for an as-sprayed sample (PS-4).

direction. Using values for $\varepsilon_{11}$ and $\varepsilon_{22}$ from the plot, Poisson's ratio varies between 0.10 and 0.15 for a coating $86 \%$ dense. Green et al. ${ }^{19}$ noted that, for conventionally sintered alumina, a Poisson's ratio of 0.18 would be expected for a body with similar density to that of the as-sprayed coating, whereas Poisson's ratio for a fully dense alumina is $\approx 0.21 .^{19}$ Certainly, the anisotropy of the microstructure and the porosity distribution would play a key role in Poisson's ratio.

(B) Decreasing Modulus with Increasing Applied Stress: Figure 7 compares the compressive modulus of several tubes, as a function of the maximum applied stress and percent density. The modulus was calculated in the initial loading region of the stress-strain curve and ranged from 96 to $56 \mathrm{GPa}$. For an effective lamella diameter of $12 \mu \mathrm{m}$, a strain gauge with an area of $5.25 \mathrm{~mm}^{2}$ would cover $\approx 60000$ lamellae. Thus, the present method of determining the modulus measures an average value. However, the reported modulus values correspond well with methods that probe a smaller area, as in the case of using indentation methods. ${ }^{20}$

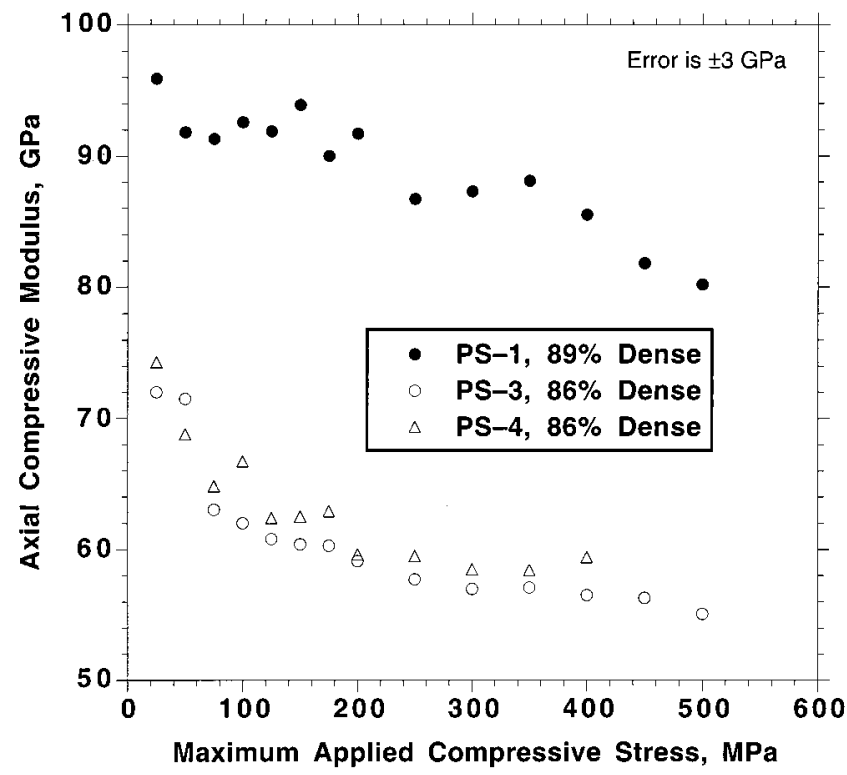

Fig. 7. Plot of compressive modulus in the axial direction, as a function of the maximum applied compressive stress, for several tubes.

A decrease in modulus was noted during the increased-stress cyclic loading for all tubes tested. For example, the modulus for PS-1 was $96 \mathrm{GPa}$ when the sample was loaded to $25 \mathrm{MPa}$ and 80 $\mathrm{GPa}$ when it was loaded to $500 \mathrm{MPa}$, a drop of $17 \%$. Also noted in Fig. 7 is the hypersensitivity of the compressive modulus with small changes in density. An $\approx 3 \%$ increase in porosity decreased the modulus by $20 \%-33 \%$. This decrease was observed previously $^{12}$ in plasma-sprayed YSZ, where a $3 \%$ increase in porosity decreased the modulus by $\approx 50 \%-70 \%$.

(C) Room-Temperature, Time-Dependent Stress-Strain Phenomena: Shown in Fig. 8(a) is a plot of the average $\varepsilon_{22}$ for an as-sprayed tube subjected to a $1 \mathrm{~h}$ hold at $200 \mathrm{MPa}$. The axial strain did not remain constant but rather exhibited a timedependent mechanical response, demonstrating that the tube was being compressed over time. A plot of $\ln \left(\mathrm{d} \varepsilon_{22} / \mathrm{d} t\right)$, made using the data in the $1 \mathrm{~h}$ hold region (see Fig. 8(b)), revealed that the damage rate was very high initially, then decreased with time. The time-dependent stress-strain phenomena from the as-sprayed tube were compared with those from a tube subjected to a $50 \mathrm{~h}$ heat treatment at $1300^{\circ} \mathrm{C}$ before a $1 \mathrm{~h}$ hold at $450 \mathrm{MPa}$ (not shown). In the heat-treated tube, the $\varepsilon_{22}$ value was constant for up to $1 \mathrm{~h}$, despite being loaded to similar strains. Thus, $\mathrm{d} \varepsilon_{22} / \mathrm{d} t$ was zero for the heat-treated material.

Also shown in Fig. 8(a) are the acoustic emissions generated during the load/unloading of the sample. Most of these events occurred as the stress reached the maximum stress (200 MPa), with recorded intensities of 40-100 dB. Correspondingly, most of the deformation occurred in this region. Within the $1 \mathrm{~h}$ hold, a few more AE signals were generated by the sample, corresponding to the smaller changes in total deformation.

\section{Discussion}

Intrinsic to all plasma-sprayed coatings are their highly defective microstructures. It is well understood that plasma-sprayed coatings are assembled from lamellae that result from the collision of molten powders with a substrate or from previously deposited lamellae. How these lamellae are stacked on top of each other during each pass of the torch determines the amount and type of microstructural defects in the coating. These defects manifest themselves primarily as porosity, microcracks, and unmelted powders. A bimodal distribution of porosity exists in plasmasprayed coatings, varying from large-scale porosity $(>1 \mu \mathrm{m})$ to small-scale porosity $(\approx 0.1 \mu \mathrm{m}){ }^{21}$ The smaller porosity is often 

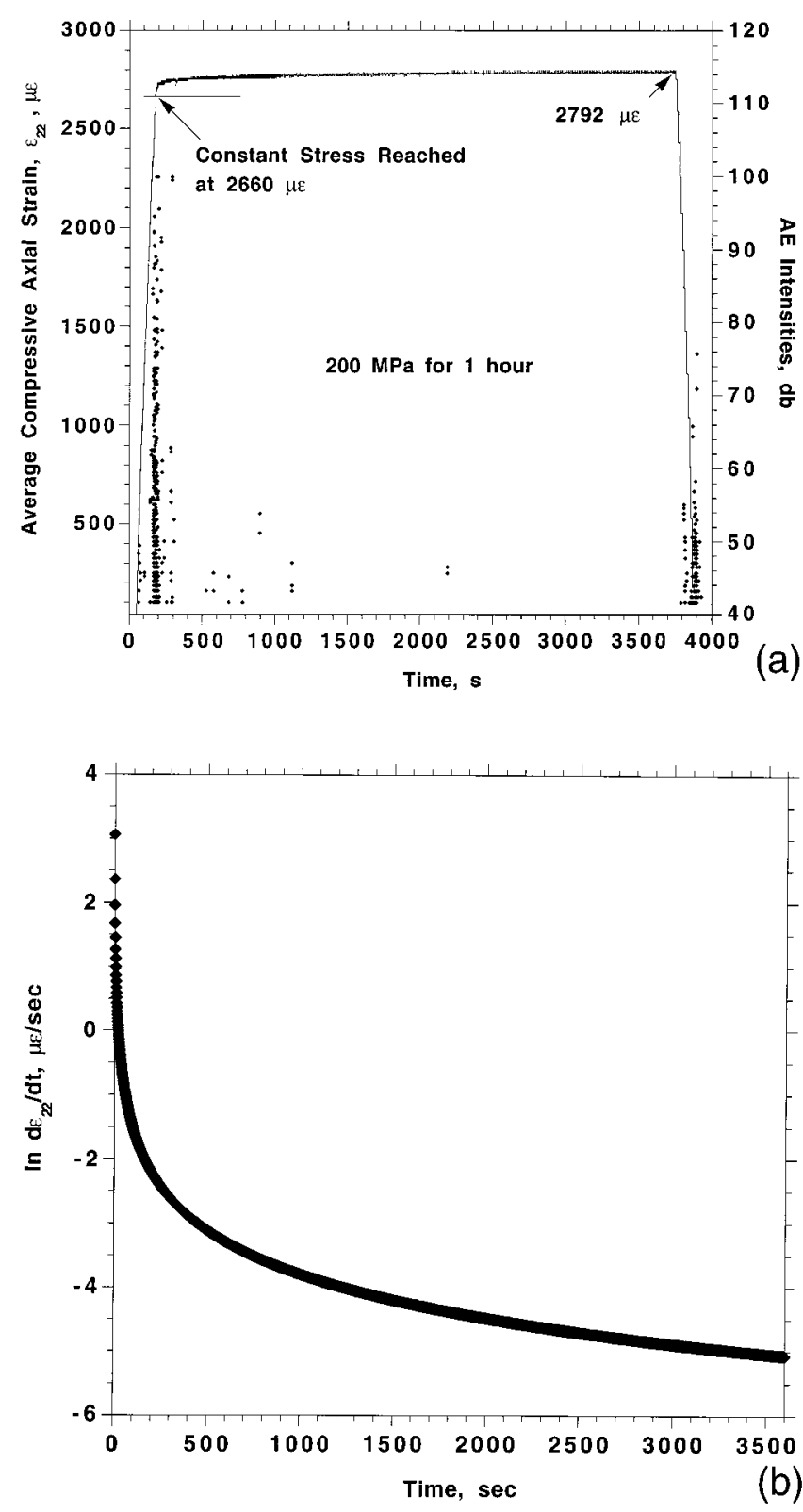

Fig. 8. Plots of (a) $\varepsilon_{22}$ and $\mathrm{AE}$ output for an as-sprayed coating, as a function of time, for a $1 \mathrm{~h}$ hold at $200 \mathrm{MPa}$ and (b) $\ln \left(\mathrm{d} \varepsilon_{22} / \mathrm{d} t\right)$ versus time for the $1 \mathrm{~h}$ hold region only in (a).

located at the interfaces between lamellae, as shown in Fig. 2(b), typically reducing the contact area between lamellae to $\approx 20 \%$. ${ }^{22}$ The microcracks within the lamellae are caused by thermal stresses that arise on cooling. The stresses cause the flattened lamella to crack into smaller pieces, with the cracks orienting themselves parallel to the spray direction. In the specific case of plasmaspraying alumina, unmelted or partially melted powder is manifest as $\alpha-\mathrm{Al}_{2} \mathrm{O}_{3}{ }^{23}$ (the same as the starting powder). The role of unmelted particles on the mechanical response is being investigated in a future paper. ${ }^{24}$ Defects play a major role in the mechanical response of ceramics, and observing their changes will likely give evidence of the operative deformation mechanisms.

The response of porous or microcracked brittle materials subjected to compressive stress states has been addressed by previous researchers. ${ }^{25-28}$ First, considering porosity, Sammis and Ashby ${ }^{25}$ showed that pores interact with the applied compressive stress, forming cracks that propagate parallel to the loading direction. As greater stress is applied, damage continues via extension of cracks, until the pores link up with cracks originating from other pores, forming narrow columns, as shown in Fig. 9(a).

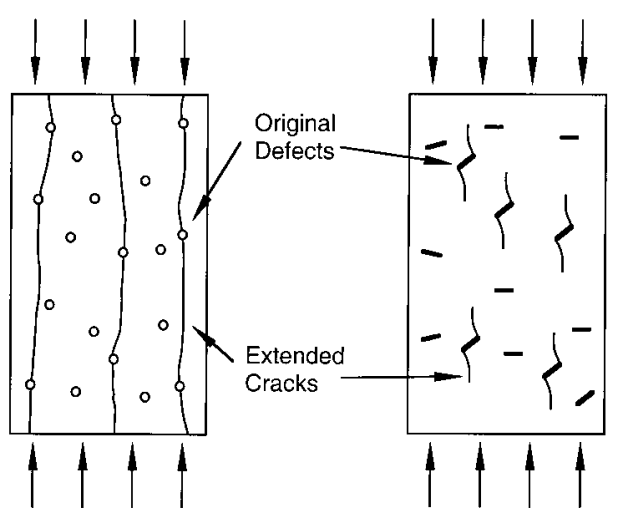

(a)

(b)

Fig. 9. Schematics showing the interaction of (a) porosity and (b) microcracks with compressive stress states. For both defects, cracks can ultimately grow and connect with other extended cracks, forming narrow columns. (Adapted from Refs. 25 and 26.)

Second, microcracks oriented off the primary loading axis (see Fig. 9(b)) are subjected to a shear stress, as demonstrated by Ashby and Hallam. ${ }^{26}$ At the tips of each crack, a tensile stress develops under compressive loading. If the tensile stress is of sufficient magnitude, a crack nucleates and propagates, forming "wing" cracks that ultimately orient themselves parallel to the loading direction. This crack orientation is favored, because it is perpendicular to the greatest tensile stress. Further loading extends the cracks, resulting in narrow columns similar to that resulting from porosity. The narrow columns formed for each type of defect are ultimately easy to buckle.

The studied Sammis and Ashby ${ }^{25}$ and Ashby and Hallam ${ }^{26}$ defect microstructures closely resemble the plasma-sprayed microstructure, because both porosity (located between lamellae) and microcracks (within lamellae) exist. As such, those models are consistent with the mechanical response and microstructural observations of the plasma-sprayed coatings. The AE results clearly indicate that damage by crack pop-in and growth is the operative deformation mechanism in the compressively loaded plasmasprayed tubes.

Evidence of this deformation mechanism was also observed in the TEM analysis, as shown in Fig. 10(a), a bright-field TEM micrograph from a sample that was tested through failure. Apparent in the micrograph are adjacent lamellae that have been split by long interlamellae cracks. Closer examination reveals small, porous regions between the lamellae. Also apparent in the micrograph is a crack that has propagated through these unbonded regions, following a weak path that would include the porosity. Because TEM sample preparation is, by its very nature, destructive, these types of regions, although not shown here, were not observed in identically prepared samples before testing. Also, there were regions investigated in the sample tested to failure that showed no damage (see Fig. 2(b)). Investigations of the fractured TEM samples revealed no other evidence that would point to other deformation mechanisms.

Hysteresis results on unloading, because the material has been damaged during the loading cycle (see Fig. 3). Because the damage is proportional to the loading (see Fig. 5), greater permanent strain is observed as load is increased. Sammis and Ashby ${ }^{25}$ show that the modulus should decrease with cracking, a phenomenon observed in the current data set (see Fig. 7). The modulus steadily decreases because the extent of damage, in the form of cracks, increases with each cycle. As a result, many cycles are required to nucleate, propagate, and link up enough cracks to cause failure.

The question remains as to why the heat-treated sample, of equivalent density, shows markedly different behavior. Two possibilities exist. First, the morphology of the grains has been altered. Figure $10(\mathrm{~b})$ is a TEM micrograph of the heat-treated alumina in 

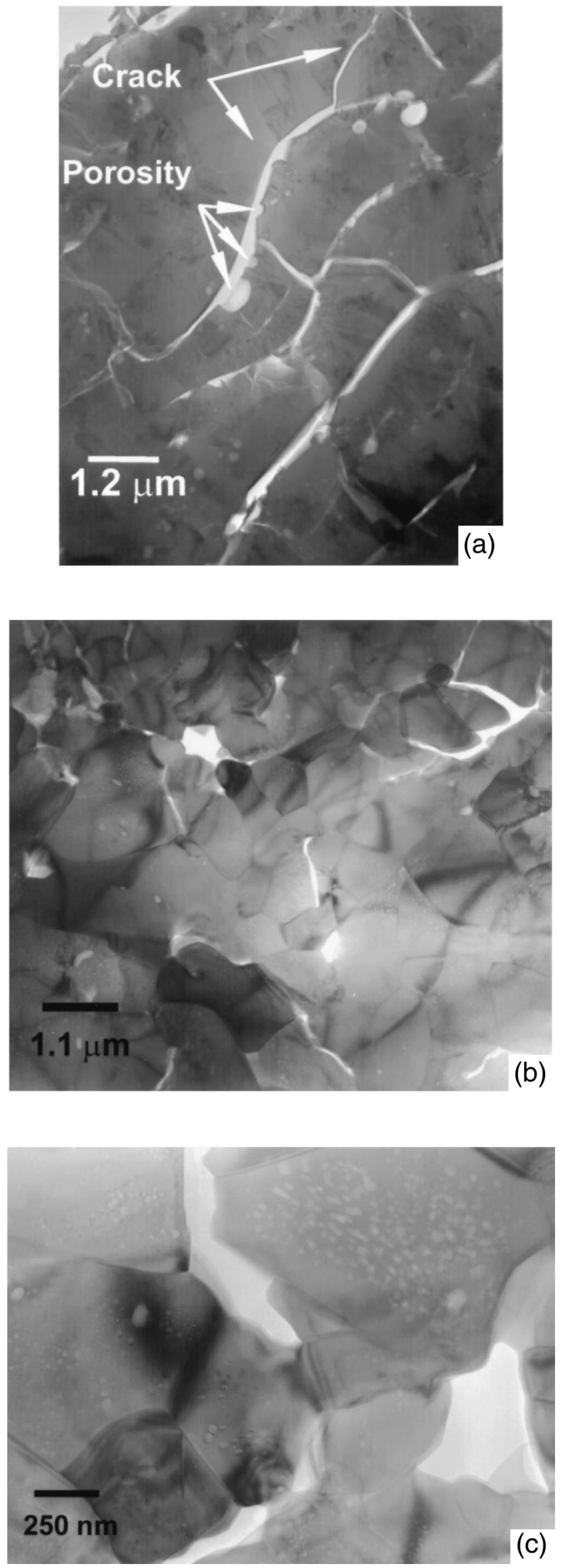

Fig. 10. Bright-field TEM micrographs of (a) sample fractured at 400 $\mathrm{MPa}$, in a damaged area, and (b) and (c) sample heat-treated for $50 \mathrm{~h}$ at $1300^{\circ} \mathrm{C}$ and tested. the identical orientation and at the same magnification as the as-sprayed alumina shown in Fig. 2(b). Neither individual lamellae nor columnar grains are observed. Rather, equiaxed grains with good contact (see Fig. 10(c)) are apparent. Because the grains have sintered together, the microstructure does not possess the defects to accommodate strain via numerous crack nucleation and growth events. Thus, no hysteresis is observed during loading/unloading cycles. Another result of the sintering is the increase in modulus from $\approx 80$ to $170 \mathrm{GPa}$. Because minimum damage occurs during the increased-stress cyclic loading of the heat-treated material, the modulus remains constant throughout the mechanical cycling.

Second, a major polymorphic change occurs in the alumina, transforming it from $\gamma-\mathrm{Al}_{2} \mathrm{O}_{3}$ to $\alpha-\mathrm{Al}_{2} \mathrm{O}_{3}$, as a result of the heat treatment. Environmentally assisted crack growth would provide a valid explanation for the time-dependent strain behavior observed in the $\gamma-\mathrm{Al}_{2} \mathrm{O}_{3}$ samples. Although it is well established that both single-crystal ${ }^{29}$ and polycrystalline ${ }^{30-32} \alpha-\mathrm{Al}_{2} \mathrm{O}_{3}$ exhibit slow crack growth in the presence of moisture, less is known about $\gamma-\mathrm{Al}_{2} \mathrm{O}_{3}$, the phase that comprises the bulk of the coating. However, we can invoke an analogy to environmentally assisted cracking in strained silicate structures. Michalske and Bunker ${ }^{33}$ demonstrated experimentally and through molecular orbital calculations that strained polymorphs $\left(\mathrm{SiO}_{2}-\mathrm{W}\right)$ were more chemically reactive than the more stable silicates. It follows, then, that $\gamma-\mathrm{Al}_{2} \mathrm{O}_{3}$, known for its reactivity in catalytic applications, ${ }^{34}$ may have a greater susceptibility to environmentally assisted crack growth than its most stable polymorph, $\alpha-\mathrm{Al}_{2} \mathrm{O}_{3}$. Thus, for the applied stresses and hold times used currently, the time-dependent behavior may be more apparent for the $\gamma-\mathrm{Al}_{2} \mathrm{O}_{3}$ phase than the $\alpha-\mathrm{Al}_{2} \mathrm{O}_{3}$ phase. Ultimately, further experimentation is required to delineate the time-dependent mechanical response of as-sprayed coatings.

\section{Conclusions}

Cylindrical stand-alone coatings of plasma-sprayed alumina were tested in compression, using cyclic loading with monotonically increasing applied stresses, to evaluate their mechanical response. Hysteresis was observed in the loading/unloading strain response, as well as decreasing modulus with each subsequent loading/unloading cycle. This unusual mechanical response has been linked to the intrinsic defects present in plasma-sprayed coatings, specifically interlamellar porosity and microcracks. During deformation, cracks are proposed to nucleate at the porous interface between adjacent lamellae, ultimately propagating parallel to the load application. Link up of these cracks via repeated loading to higher stresses ultimately results in failure. AE verified crack growth, observed in TEM images of a failed ceramic tube.

\section{Acknowledgments}

The authors gratefully acknowledge the financial support of the U.S. Department of Energy, Federal Energy Technology Center. The authors also wish to thank Dan Marron of the Infrastructure Technology Institute for assistance setting up the data-acquisition hardware and software used in this study, Mark Sinew for his mechanical testing expertise in solving alignment problems associated with testing tubes, and Rick Marzec for his assistance with fabrication of the plasma-sprayed tubes.

\section{References}

${ }^{1}$ J. R. Shadley, E. F. Rybicki, Y. Xiong, R. T. R. McGrann, and A. C. Savarimuthu, "An ASM Recommended Practice for Evaluation of Young's Modulus and Poisson's Ratio of Thermal Spray Coatings Bonded to a Substrate," presented at the International Thermal Spray Conference, Montreal, Quebec, Canada, May 8-11, 2000.

${ }^{2}$ O. Unal and D. J. Sordelet, "In-Plane Tensile Strength and Residual Stress in Thick $\mathrm{Al}_{2} \mathrm{O}_{3}$ Coatings on Aluminum Alloys," Scr. Mater., 42, 631-35 (2000).

${ }^{3}$ L. Lelait, S. Alperine, C. Diot, and M. Mevrel, "Thermal Barrier Coatings: Microstructural Investigation after Annealing," Mater. Sci. Eng. A, 121, 475-82 (1989).

${ }^{4}$ S. M. Meier, D. M. Nissley, K. D. Sheffler, and T. A. Cruse, "Thermal Barrier Coating Life Prediction Model Development," J. Eng. Gas Turbines Power, 114 [4] 258-63 (1992) 
${ }^{5}$ R. A. Miller and C. E. Lowell, "Failure Mechanisms of Thermal Barrier Coatings Exposed to Elevated Temperatures," Thin Solid Films, 95, 265-73 (1982).

${ }^{6}$ W. J. Brindley and R. A. Miller, "Thermal Barrier Coating Life and Isothermal Oxidation of Low-Pressure Plasma-Sprayed Bondcoat Alloys," Surf. Coat. Technol., 43-44, 446-57 (1990).

${ }^{7}$ A. J. Allen, G. G. Long, J. Wallace, J. Ilavsky, C. C. Berndt, and H. Herman, "Microstructural Changes in YSZ Deposits during Annealing"; pp. 228-33 in United Thermal Spray Conference (Dusseldorf, Germany, Mar. 17-19, 1999). Edited by E. Lugscheider and P. A. Kammer. DVS Publishers, 1999.

${ }^{8}$ E. F. Rejda, D. F. Socie, and B. Beardsley, "Fatigue Behavior of a Plasma-Sprayed $8 \% \mathrm{Y}_{2} \mathrm{O}_{3}-\mathrm{ZrO}_{2}$ Thermal Barrier Coating," Fatigue Fract. Eng. Mater. Struct., 20 [7]1043-50 (1997).

${ }^{9}$ K. F. Wesling, D. F. Socie, and B. Beardsley, "Fatigue of Thick Thermal Barrier Coatings," J. Am. Ceram. Soc., 77 [7] 1863-68 (1994).

${ }^{10}$ S. R. Choi, D. Zhu, and R. A. Miller, "High-Temperature Slow Crack Growth, Fracture Toughness, and Room-Temperature Deformation Behavior of PlasmaSprayed $\mathrm{ZrO}_{2}-8$ wt\% $\mathrm{Y}_{2} \mathrm{O}_{3}$," Ceram. Eng. Sci. Proc., 19 [4] 293-301 (1998).

${ }^{11}$ R. W. Trice and K. T. Faber, "The Role of Lamella Morphology on the Microstructural Development and Mechanical Properties of Small-Particle PlasmaSprayed Alumina," J. Am. Ceram. Soc., 83 [4] 889-96 (2000).

${ }^{12}$ T. A. Cruse, B. P. Johnsen, and A. Nagy, "Mechanical Properties Testing and Results for Thermal Barrier Coatings," J. Therm. Spray Technol., 6 [1] 57-66 (1997).

${ }^{13}$ B. P. Johnsen, T. A. Cruse, R. A. Miller, and W. J. Brindley, "Compressive Fatigue of a Plasma-Sprayed $\mathrm{ZrO}_{2}-8$ wt $\% \mathrm{Y}_{2} \mathrm{O}_{3}$ and $\mathrm{ZrO}_{2}-10$ wt $\%$ NiCrAlCoY TBC," J. Eng. Mater. Technol., 117 [7] 305-10 (1995).

${ }^{14}$ T. F. Bernecki and D. R. Marron, "Small-Particle Plasma-Spray Apparatus, Method and Coated Article," U. S. Patent No. 5744 777, 1998, and U. S. Patent No. $5858470,1999$.

15"Standard Test Method for Water Absorption, Bulk Density, Apparent Porosity, and Apparent Specific Gravity of Fired Whiteware Products," ASTM Standard C373-72. American Society for Testing and Materials, West Conshohocken, PA, 1982.

${ }^{16}$ C.-K. Lin, C. C. Berndt, S-H. Leigh, and K. Murakami, "Acoustic Emission Studies of Alumina-13\% Titania Free-Standing Forms during Four-Point Tests," J. Am. Ceram. Soc., 80 [9] 2382-94 (1997).

${ }^{17}$ C.-K. Lin, S.-H. Leigh, and C. C. Berndt, "Acoustic Emission Responses of Plasma-Sprayed Alumina-3\% Titania Deposits," Thin Solid Films, 310, 108-14 (1997).

18 "Standard Terminology for Nondestructive Examinations"; p. 607 in ASTM Standard No. E1316-93b. American Society for Testing and Materials, West Conshohocken, PA, 1993.
${ }^{19}$ D. J. Green, C. Nader, and R. Brezny, "The Elastic Behavior of Partially Sintered Alumina"; pp. 345-56 in Ceramic Transactions, Vol. 7, Sintering of Advanced Ceramics. Edited by C.A. Handwerker, J. E. Blendell, and W. Kaysser. American Ceramic Society, Westerville, OH, 1990.

${ }^{20}$ S-H. Leigh, C-K Lin, and C. C. Berndt, "Elastic Response of Thermal Spray Deposits under Indentation Tests," J. Am. Ceram. Soc., 80 [8] $2093-99$ (1997).

${ }^{21}$ R. McPherson, "A Review of Microstructure and Properties of Plasma-Sprayed Ceramic Coatings," Surf. Coat. Technol., 39/40, 173-81 (1989).

${ }^{22}$ A. R. de Arellano-Lopez and K. T. Faber, "Microstructural Characterization of Small-Particle Plasma-Spray Coatings," J. Am. Ceram. Soc., 82 [8] 2204-208 (1999).

${ }^{23} \mathrm{R}$. McPherson, "On the Formation of Thermally Sprayed Alumina Coatings," $J$. Mater. Sci. Eng., 15, 3141-49 (1980).

${ }^{24}$ R. W. Trice, C. Batson, C. Scharff, and K. T. Faber, "The Role of Starting Powder Size on the Compressive Response of Stand-Alone Plasma-Sprayed Alumina Coatings," submitted to J. Mater. Sci.

${ }^{25}$ C. G. Sammis and M. F. Ashby, "The Failure of Brittle Porous Solids under Compressive Stress States," Acta Metall., 34 [3] 511-26 (1986).

${ }^{26}$ M. F. Ashby and S. D. Hallam, "The Failure of Brittle Solids Containing Small Cracks under Compressive Stress States," Acta Metall., 34 [3] 497-510 (1986).

${ }^{27}$ M. Adams and G. Sines, "A Statistical, Micromechanical Theory of the Compressive Strength of Brittle Materials," J. Am. Ceram. Soc., 61 [3-4] 126-31 (1978).

${ }^{28}$ M. Adams and G. Sines, "Spalling and Cracking in Alumina in Compression," J. Am. Ceram. Soc., 60 [5-6] 221-26 (1977).

${ }^{29}$ S. M. Wiederhorn, "Subcritical Crack Growth in Ceramics"; pp. 613-46 in Microstructure, Materials, and Applications, Fracture Mechanics of Ceramics, Vol. 2. Edited by R. C. Brandt, D. P. H. Hasselman, and F. F. Lange. Plenum Press, New York, 1974

${ }^{30}$ K. Zeng, K. Breder, and D. Rowcliffe, "Comparison of Slow Crack Growth Behavior in Alumina and SiC-Whisker-Reinforced Alumina," J. Am. Ceram. Soc., 76 [7] 1673-80 (1993)

${ }^{31}$ S. R. Choi, "Effect of Environment on Fracture Toughness of 96 wt\% Alumina," Scr. Metall., 29, 189-92 (1993).

${ }^{32}$ T. Okada, G. Sines, and D. Green, "Crack Origins and Microcracking in Delayed Fracture of Alumina," J. Am. Ceram. Soc., 65 [5] C-64-C-65 (1982).

${ }^{33}$ T. A. Michalske and B. C. Bunker, "Slow Fracture Model Based on Strained Silicate Structures," J. Appl. Phys., 56 [10] 2686-93 (1984).

${ }^{34}$ C. L. Thomas, Catalytic Processes and Proven Catalysts; p. 246. Academic Press, New York, 1970. 